\title{
Fabricated Green buildings measure the development of new villages
}

\author{
Sun Yanli1 ${ }^{1, *}$, Zhang $\mathrm{Di}^{2}$ \\ ${ }^{1}$ School of Management, Associate professor, Shenyang Jianzhu University, China \\ ${ }^{2}$ School of Management, Master's degree, Shenyang Jianzhu University, China
}

\begin{abstract}
With the renovation of the architectural design concept and the progress of architectural technology, the requirement of green environmental protection in architectural design and construction is increasing in our country. The article mainly explains the development of assembled green buildings in the construction of new countryside. It is hoped that it can provide a reference for relevant units and workers, and promote the development of assembled green building in the new countryside.
\end{abstract}

\section{The development status of prefabricated green building}

\subsection{The development trend of prefabricated green buildings in the new countryside}

The development trend of prefabricated green buildings in the New Countryside

In the construction of new countryside, restricted by its conditions and economic level, development of rural buildings is relatively backward, and rural housing and related buildings have problems such as long construction period, poor quality, heavy economic burden, serious waste of resources, and large environmental pollution. The green prefabricated building has the advantages of a short construction period, good quality, low construction cost, resource-saving, and environmental protection. Its application and promotion are the inevitable trends in the future of new rural areas construction. On the premise of ensuring the basic functions of building materials, it pursues the development concept of healthy, sustainable, and harmonious coexistence. People's concepts and consciousness are gradually changing to green building materials and ecological building materials. The pursuit of materials is non-toxic and harmless, without damage to health and adverse impact on the environment.

The change of the real estate market makes the construction industry shift its target to the rural market. The prefabricated building system of steel structure + integral board not only conforms to the characteristics of the rural market with many monomers but also meets the diverse climate and geographical conditions in rural areas. At the same time, the insulation effect of the integral board provides a strong guarantee for improving the rural living conditions, showing unique advantages in the rural market potential. With the implementation of the Rural Revitalization Strategy, the Ministry of Housing and urban-rural development has gradually strengthened the promotion of steel structures, and the local government has continuously improved the indicators of prefabricated buildings, which ushered in the explosive development period of steel structure prefabricated buildings. To promote the application of modern rural housing construction methods, we should apply new green energysaving technologies, new products, and new processes, explore prefabricated green building technology, pay attention to the integrated design of rural housing, and integrate green energy-saving technology and facilities into it.

\subsection{Advantages of assembled green building}

Traditional rural buildings are mainly brick-concrete structures, which need to be further improved in structural form, sound insulation, heat insulation, moisture-proof, comfort, building life cycle, and so on. Although the traditional building in rural areas has the advantage of local materials, there is a long construction cycle, lack of traditional craftsmen, serious waste of resources, low coordination with the environment, and so on. The prefabricated building makes up for the defects in the design concept, construction phase, and life cycle of traditional rural buildings, and has the advantages of good quality, short construction period, energy conservation and environmental protection, and saving manpower and material resources.

(1) Guarantee quality of the project. Traditional on-site construction is limited by the uneven of workers, quality accidents occur from time to time. The prefabricated building components are manufactured in a prefabrication plant, where temperature and humidity conditions are controlled to ensure a better quality of the components.

(2) Reduce Safety Concerns. Compared with traditional construction, the components of the prefabricated building are transported to the site and

\footnotetext{
"Corresponding author: 1740736862@qq.com/1521899783@qq.com
} 
assembled by a professional installation team in strict accordance with the process, which greatly improves the quality of the project and reduces the potential safety hazard.

(3)Increase production efficiency. The components of the prefabricated building are mass-produced by the factory and installed using hoisting, splicing, and so on, which saves the corresponding construction process and greatly improves the construction efficiency.

(4)Reduce Labor costs cost. The use of prefabricated plant construction, site assembly construction, a high degree of mechanization, reduce site construction and management, the number of prefabricated buildings nearly 10 times.

(5)Low Carbon energy saving and environmental protection. Prefabricated building circular economy features remarkable because the template used can be recycled, saving a lot of scaffolding and template operations, saving wood resources. Also, as the components are produced in the factory, the site wet operation is less, greatly reducing noise.

\section{The main existing problems of rural housing in China at present}

At present, most of the rural areas have problems such as people coming to the cities to work. Rural houses have been left idle for a long time, are old and dilapidated, and most of them have become dangerous. Every year, there are several cases of houses collapsing and people being injured or killed as a result of snowstorms and other disasters, not to mention the massive loss of life in force majeure like the earthquake. Most of the rural houses in our country adopt brick-concrete structures, which are built at will and have no professionals to carry out the overall design of the buildings. This causes the rural residential structure to not conform to China's seismic norms and residential layout chaos, development of rural economic constraints. Backward industrial technology, no good architectural design, and layout of confusion and other reasons will not only cause residential security risks but also lead to the reduction of arable land, traffic inconvenience, and other consequences.

\section{Measurement of the energy-saving benefit of assembled green building}

China's new rural construction process is deepening day by day, and the country's demand for building a resourcesaving and environment-friendly new rural area is increasing. At the same time, the new assembled green building gradually replaces the traditional cast-in-place building with high energy consumption and high emission, which has become the main trend of industry development. Compared with traditional architecture, the assembly type has the advantages of shortening the construction cycle, improving engineering quality, saving resources and energy, and promoting environmental protection. Therefore, an in-depth understanding of the assembly of the integral building in the ecological environment of the green energy-saving advantages for rural construction, to promote the development of the prefabricated building is of great significance.

\subsection{High-performance envelope}

Envelope heat transfer and air infiltration heat transfer are the two main components of building heat consumption. The building envelope is the main body of building space closed, is the main body of heat exchange between the building and outside, and is one of the key factors to determine building energy consumption. Most of the existing buildings in rural areas have some problems, such as low building standards, weak thermal performance of building envelope, the poor effect of energy-saving, and low comfort. High-performance envelope design is a key element of ultra-low energy consumption buildings in rural areas. The project is designed according to the technical requirements of the passive green building with ultra-low energy consumption. Through the design optimization of the envelope structure, the building has high-quality thermal insulation performance, thus achieving the goal of energy-saving and comfort.

The enclosure structure of precast members can be designed with "Sandwich type" exterior wall insulation, which has the characteristics of delaying the attenuation of the insulation performance of the insulation material and prolonging the insulation effect of the building in use, the utility model can effectively reduce the overall energy consumption of the building and play a certain control role in the building energy conservation. Compared with the traditional buildings, the thermal index per unit area can be reduced by $26.9 \%$, and the annual maximum thermal load can be reduced by $2.3 \%$. The total cumulative annual energy consumption load is much smaller than that of traditional buildings, so energy saving, especially in the northern winter heating season, the energy-saving effect of the assembly-type Green building is very obvious.

\subsection{Environmental benefits}

The environmental benefits of the fabricated green building are mainly presented in the aspect of building carbon emission reduction. Considering the whole life cycle of the fabricated green building, the construction phase accounts for a large proportion of the total carbon emissions of the building throughout its life cycle. In the construction process, $80.6 \%-85.7 \%$ of the carbon emissions come from their building materials, 7.4\%-9.6\% of the carbon emissions come from the construction equipment energy consumption; $6.1 \%-8.4 \%$ of carbon emissions come from the energy consumption of building materials during transportation.

(1)Measurement method of total carbon emission from buildings

The total carbon emission of building materials in a building consists of the carbon emission from the production, transportation, replacement, and posttreatment of the building materials. The calculation formula is as follows:

$$
\mathrm{Q}=\mathrm{Q} 1+\mathrm{Q} 2+\mathrm{Q} 3+\mathrm{Q} 4
$$


$\mathrm{Q}$ is the total carbon emission from building materials in a building, Q1, Q2, Q3 and Q4 are the total carbon emissions from the production, transportation, replacement, and post-treatment of building materials.

(2) Construction,production, transportation, and construction phase carbon emission measurement

This paper mainly evaluates and analyzes the carbon emission in the physical and chemical stages of the production, transportation, and construction of precast components. Carbon emissions account for over $82 \%$ of the total carbon emissions. From the point of view of energy-saving and emission-reducing, resource-saving, and environment-protecting, this paper measures the carbon emission evaluation system of green prefabricated building, and analyzes the influencing factors of carbon emission in green prefabricated building, the evaluation index of Carbon Emission in green prefabricated building stage is studied from different dimensions such as investment, resource utilization, energy utilization, land, building, waste and so on, and the evaluation system of different levels is constructed, the Comprehensive Evaluation Index System of carbon emission in the stage of assembled green building is established, and the concrete index levels are given in Table 1.

The weight of each index is calculated by the method of the characteristic root of the analytic hierarchy process (AHP), and the weight order of each index in the stage of prefabricated green building is obtained respectively. The results are in Table 1.

Table 1. Weights of indicators at various levels.

\begin{tabular}{|c|c|c|c|c|c|c|}
\hline Criterion Layer & $\begin{array}{c}\text { Criterion } \\
\text { weight }\end{array}$ & Indicators & $\begin{array}{c}\text { Index } \\
\text { weight }\end{array}$ & Subindex & $\begin{array}{c}\text { Sub-index } \\
\text { weight }\end{array}$ & $\begin{array}{c}\text { Total } \\
\text { weight }\end{array}$ \\
\hline \multirow{13}{*}{$\begin{array}{l}\text { Resources and } \\
\text { energy use }\end{array}$} & \multirow{13}{*}{0.750} & Investment quota & 0.0614 & Investment quota & 1 & 0.0461 \\
\hline & & \multirow{2}{*}{$\begin{array}{c}\text { Resource } \\
\text { consumption }\end{array}$} & \multirow{2}{*}{0.4134} & Main material & 0.75 & 0.2325 \\
\hline & & & & Secondary material & 0.25 & 0.0775 \\
\hline & & \multirow{4}{*}{$\begin{array}{c}\text { Energy } \\
\text { consumption }\end{array}$} & \multirow{4}{*}{0.2319} & Electricity & 0.4444 & 0.0773 \\
\hline & & & & Diesel oil & 0.2222 & 0.0386 \\
\hline & & & & Gasoline & 0.2222 & 0.0386 \\
\hline & & & & Coal & 0.1111 & 0.0193 \\
\hline & & Temporary land & 0.2319 & Land & 1 & 0.1739 \\
\hline & & \multirow{5}{*}{$\begin{array}{c}\text { Energy } \\
\text { Conservation }\end{array}$} & \multirow{5}{*}{0.0614} & Energy saving & 0.4 & 0.0184 \\
\hline & & & & Fuel economy & 0.2 & 0.0092 \\
\hline & & & & Coal Saving & 0.1 & 0.0046 \\
\hline & & & & Land Conservation & 0.1 & 0.0046 \\
\hline & & & & $\begin{array}{l}\text { Use of clean and renewable } \\
\text { energy }\end{array}$ & 0.2 & 0.0092 \\
\hline \multirow{6}{*}{$\begin{array}{l}\text { Construction and } \\
\text { ecological } \\
\text { environment }\end{array}$} & \multirow{6}{*}{0.250} & \multirow{4}{*}{$\begin{array}{l}\text { Construction } \\
\text { Organization }\end{array}$} & \multirow{4}{*}{0.5} & Personnel Organization & 0.1667 & 0.0208 \\
\hline & & & & $\begin{array}{c}\text { Application of new } \\
\text { technology and new process }\end{array}$ & 0.3333 & 0.0417 \\
\hline & & & & $\begin{array}{l}\text { The use of advanced } \\
\text { construction machinery }\end{array}$ & 0.3333 & 0.0417 \\
\hline & & & & $\begin{array}{l}\text { Design and management of } \\
\text { Construction Organization }\end{array}$ & 0.1667 & 0.0208 \\
\hline & & \multirow{2}{*}{ Waste matter } & \multirow{2}{*}{0.5} & Quantity of construction waste & 0.5 & 0.0625 \\
\hline & & & & $\begin{array}{l}\text { Recycling of construction } \\
\text { waste }\end{array}$ & 0.5 & 0.0625 \\
\hline
\end{tabular}




\subsection{Solar Power System}

Rural Public Infrastructure is not well-equipped, facing huge energy challenges, scattered villages, low population density, and building density, most of which are outside the regional heating zone. According to statistics, $80 \%$ of rural indoor heating in northern rural areas relies on stoves and heating brick beds, of which $74 \%$ rely on coal as a heat source, the effective utilization rate is only $15 \%$ $25 \%$. The smoke emitted by this heating method seriously affects the safety and health of the population and the atmospheric environment. Rural buildings need to explore and apply new energy-saving technology, using new clean energy, the photovoltaic panel is one of the effective means to provide energy for power generation and reduce building energy consumption.

To reduce energy inequality, improve the living conditions of rural residents and achieve the goal of comprehensive energy conservation and emission reduction, photovoltaic power generation systems can be introduced in rural areas and solar energy can be used as renewable energy. Installation of silicon solar panels on the roofs of buildings and Verandahs to demonstrate the use of clean energy in rural areas.

\section{Suggestions on the development of assembled green building in the construction of new countryside}

(1)National level issued the new rural construction to promote the assembly of green building guidance, to create a good environment. The state should increase research on rural prefabricated buildings, formulate guidelines for popularizing fabricated green buildings in the construction of new rural areas, and form corresponding laws and regulations so that the prefabricated building will have laws to follow in the construction of new rural areas. At the same time, the guiding principle of popularizing fabricated green buildings in new rural areas construction should be integrated into prefabricated building development, especially in new residential construction and renovation projects.

(2)Building an industrial chain with a certain scale of production. In light of the reality of new rural construction, a complete industrial chain will be formed in the links of $\mathrm{R} \& \mathrm{D}$, Production, design, transportation, installation, operation, and maintenance of the prefabricated building, with the industrial chain driving production and reducing costs. At the same time, enterprises should give full play to their advantages in the industrial chain, as the main position of prefabricated building production, its production efficiency, transportation cost, construction speed, and cycle have a direct impact on the development of prefabricated building in the new countryside.

(3)Strengthen the propaganda and enhance the consciousness of villagers of assembled green buildings. Publicity should be tailored to local conditions and cater to the tastes of the majority of villagers. In the survey, it was found that the villagers were more receptive to such things as quick hands and shaking sounds, so in the promotion of assembly-style Green Building can be arranged in the form of video publicity materials can be easily understandable to the villagers but also can be properly inserted into the dialect, more grounded. At the same time, the government to increase publicity, give full play to grass-roots workers, village two-party propaganda role, vigorously promote the assembly-type green building.

(4)Popularization and application of light-duty assembly structure for easy transportation. At present, the assembled structure produced by the enterprise is mainly composed of large and medium-sized components. The main characteristics of the large and medium-sized assembled components are simple assembly, quick operation, and relatively little work, which can effectively improve the construction efficiency, but the vast majority of rural areas are located in remote, traffic inconvenience, which is not conducive to the transportation large and medium-sized fabricated structures. Considering the reality of rural construction and the current situation of the load-carrying capacity, it is more suitable to popularize the light-weight assembled structure in the new rural construction, and at the same time, the research and development the connection technology of small prefabricated components should be paid attention to, in particular, the scientific production of components, reasonable separation, safe transportation.

(5)Remold the characteristic style and features by combining the rural culture. To promote the use of fabricated green buildings in the construction of new rural areas, it is necessary to fully integrate local characteristics and culture to maintain the original atmosphere of the buildings, by combining the local characteristic building materials which can be used locally with the environmentfriendly building materials, green building materials, and prefabricated building, the sustainable of the new rural fabricated green building can be realized while reducing the construction cost. At the same time, local characteristic elements into the assembly-type green building, in the unified planning of villages and towns based on further promoting rural economic development.

\section{Conclusion}

In the construction of new countryside, the contradiction between resources and environment and large-scale construction is becoming more and more acute. To realize the sustainability of the new rural construction, it is necessary to popularize the assembled green building. As far as the building environment is concerned, the application of the assembled green building in the new rural areas is irresistible. People should further strengthen their understanding of the importance of the assembled green building and the protection of environmental resources, and formulate corresponding laws, macroeconomic Regulation and control for Green Building Assembly, establish a sound certification system, increase publicity and subsidies, and tax breaks for businesses to increase their enthusiasm. 


\section{References}

1. Liu Zhe, Zhai Zenglou. Study on the Application of Prefabricated Architecture in New Rural Housing[J].Smart Architecture and Smart City, 2021(01):28-30+33.

2. Han Xueli. Promoting Prefabricated Buildings in Rural Revitalization[J].Architecture,2020(24):36-37.

3. Sun Xian. Energy-saving design of Building Based on Stackelberg Strategy[J]. Chinese Architectural Decoration and Decoration, 2020(10):94-95.

4. Li Li. Study on the Application of Prefabricated Architecture in the Construction of New Countryside in the North Piedmont of Qinling Mountains in Xi'an[J]. Residential,2020(09):14-15.

5. Zhang Heng, Wang Dingtang, Zhang Yunpeng, Yin Didi. Feasibility Analysis of Using Prefabricated Architecture in Rural Construction[J]. Anhui Construction, 2020,27(06):122-124. 